\title{
Developing the City-Level Climate Change Master Plan: The Case of Energy Sector in Bangkok
}

\author{
Wongkot Wongsapai ${ }^{1}$, Ariyah Mekhakul ${ }^{2}$, Manaswee Arayasiri ${ }^{2}$, Kazuhito Yamada ${ }^{3}$, Mariko Fujimori ${ }^{3}$ and Hisaaki Kato ${ }^{3}$ \\ ${ }^{1}$ Faculty of Engineering, Chiang Mai University, Chiang Mai, 50200, Thailand \\ ${ }^{2}$ Bangkok Metropolitan Administration Office, Mitrmaitree Road, Din Dang, Bangkok, 10400, Thailand \\ ${ }^{3}$ Pacific Consultants Co. Ltd., 3-22 Kanda-Nishikicho, Chiyoda-ku, Tokyo, 101-8462, Japan
}

\begin{abstract}
This study focuses in the developing energy sector plan of city-level climate change master plan in Bangkok, the capital city of Thailand. The energy consumption, which consists of electricity and fossil fuels, are investigated and forecasted to be Business-as-Usual (BaU) scenario covering year 2013 to 2023 by using trend analysis. The Greenhouse Gas (GHG) emission mitigation scenario was then analyzed by applying the energy reduction from the national energy efficiency development plan as well as the own reduction activities by Bangkok Metropolitan Administration (BMA). We can conclude that if the national energy efficiency plan can fully implemented, the GHG reduction potential of the city from energy sector would be at around $18 \%$ from BAU in 2023 from all energy conservation and renewable energy measures.
\end{abstract}

\section{Introduction}

Climate change is one of the largest challenges to the current and future development of human society. The Intergovernmental Panel on Climate Change (IPCC) issued its $5^{\text {th }}$ Assessment Report [1] and warned that warming of the climate system is unequivocal, and it is extremely likely that human influence has been the dominant cause of the observed warming since the mid20th century. Hence, the long-term climate change policies and plans which focus mainly in mega-city level are very important to each country due to the very high impact to overall GHG emission of the country.

The World Bank Study[2] pointed out that Bangkok Metropolitan Region (consists of Bangkok, Nonthaburi province, Samut Prakarn province, and Pathum Thani province) might face a serious challenge by climateinduced large scale flooding within the next 50 years and urged actions to increase the readiness to cope with such extreme events [3], [4]. Bangkok area was hit by a large scale flooding in 2011 with huge economics and social loss were recorded.

BMA also implemented the Bangkok Action Plan on Global Warming Mitigation 2007-2012 [5], aiming at the GHG reduction of $15 \%$ by undertaking five initiatives as follows: (i) expansion of mass transit and improvement of traffic system, (ii) promotion of the use of renewable energy, (iii) improvement of building electricity consumption efficiency, (iv) improvement of solid waste management and wastewater treatment efficiency, and (v) expansion of park areas. After ending of the plan on 2012,
BMA policymakers had efforts to develop the next tenyear climate change master plan covering 2013 to 2023, by related sectors. This new master plan would support to the national climate change policy which Thailand will put her efforts to reduce the GHG in the range of 7 to $20 \%$ below the $\mathrm{BaU}$ in energy and transport sectors in 2020 through her NAMAs [6]-[8].

\section{Scope of this study}

\subsection{Economic sector classification}

BMA develops the Bangkok Master Plan on Climate Change 2013-2023, which is the city level long-term climate change plan. It consists of five main sectors; i.e. (i) energy efficiency and renewable energy, (ii) environmental sustainable transport, (iii) efficient solid waste management and wastewater treatment, (iv) green urban planning, and (v) adaptation planning.

This paper focuses only on the development of the energy sector, the biggest emission source of Bangkok, which includes the mitigation actions in energy efficiency and renewable development activities in Bangkok and exclude the energy consumption in transport and waste sectors. The energy sector in this study then consists of BMA governmental category and other civil category (industry, commercial, and residential parts). It should be noted here that there are only few activities of agriculture sector in Bangkok, hence we neglected the agricultural sector of this city in this study. 


\subsection{Greenhouse gas emission type}

The energy sector covers only $\mathrm{CO}_{2}$ emissions from energy utilization.

\subsection{Level of this study}

In this study, we focus mainly in the entire Bangkok area. This level (hereafter, Bkk) would focus all energy consumption and reduction potential which occur in Bangkok city, as a whole area and focus all government and non-government categories.

\subsection{Energy sector data collection}

We investigated and developed our energy data structure into two main types; (i) electricity, and (ii) thermal energy. All data are covering the year 2009-2012.

In Bangkok area, secondary data is main source of collecting energy data which is divided into the data from all sectors responsible to Bangkok entire area. All of collected data can be divided into 4 energy types which are electricity, oil, natural gas and coal as followings:

\subsubsection{Electricity}

Electricity consumption data in Bangkok is collected in secondary data from Metropolitan Electricity Authority directly requested data, not publish) in the year 20092012, covering residential, small and large general service, specific business service, government institute, non-profit organization, and temporary user and public lighting.

\subsubsection{Fuel and petroleum products}

Oil consumption data in Bangkok is collected in secondary data from Department of Energy Business

(DOEB) [9] and classified in gasohol (all types), gasoline, diesel, fuel oil, LPG and other types of oil.

\subsubsection{Natural gas}

NG data is collected in secondary data from PTT Plc. (directly requested data, not published).

\subsubsection{Coal}

Coal data is collected from Department of Alternative Energy Development and Efficiency (DEDE).

Figure 1 illustrates the Structure and sources of energy data in this study.

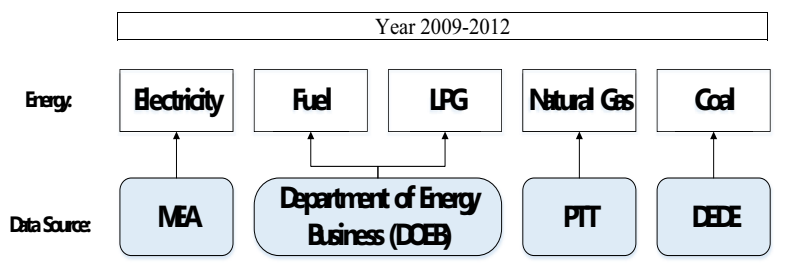

Note: Fuel means oil based petroleum products

Figure 1. Structure and sources of energy data.

\section{The BAU scenario}

Like other climate change and energy plans, it is important to see GHG emission amount by comparing cases without mitigation actions (business-as-usual or BAU) and with actions. In other words, how much GHG is reduced in quantity is one crucial approach to assessing the degree of success in mitigation actions in an objective way. In this Master Plan, GHG emissions have also been quantified for the two emission scenarios, namely the case of BAU and the case with emission reduction by taking mitigation actions.

Figure 2 illustrates the concept of how to develop our BAU of Bangkok climate change model in this study.

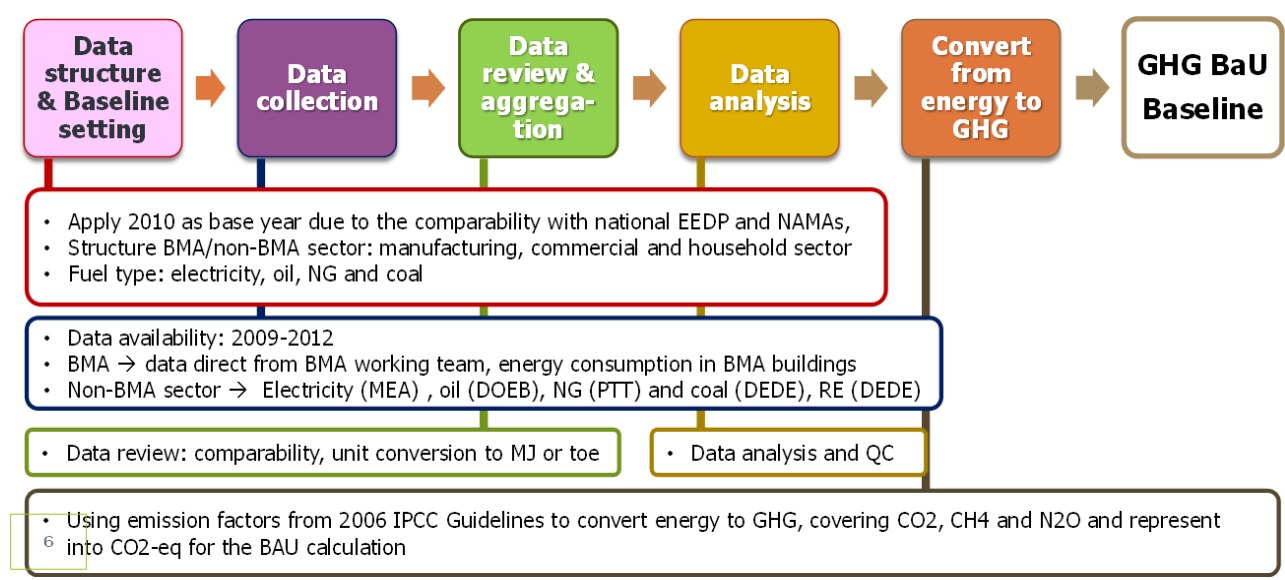

Figure 2. Flow of BAU greenhouse gas emission calculation.

By using the trend analysis from equation (1), the energy consumption in Bangkok area was then forecasted separately by each fuel type.

$$
y_{t}=\sum_{i=1}^{t-1} \frac{y_{i}}{t-1}
$$

while $y=$ forecast of $y$, in energy unit $\mathrm{t}=$ time, annually

The results of the forecasted energy consumption in BAU, presented in Table 1, would then calculate into GHG value by using equation (2). Finally, BAU in Bangkok from the year 2013 to 2023 presents in Table 2. 
Table 1. Energy consumption in BAU in Bangkok.

\begin{tabular}{l|rrl}
\hline \multicolumn{1}{|c}{ Type (Million MJ) } & \multicolumn{1}{c}{2013} & \multicolumn{1}{c}{2018} & \multicolumn{1}{l}{2023} \\
\hline Electricity & $111,960.00$ & $131,040.00$ & $150,120.00$ \\
\hline Thermal energy & $85,057.11$ & $91,665.53$ & $102,699.59$ \\
\hline Total & $197,017.11$ & $222,705.53$ & $252,819.59$ \\
\hline
\end{tabular}

Table 2. GHG emission in BAU in Bangkok.

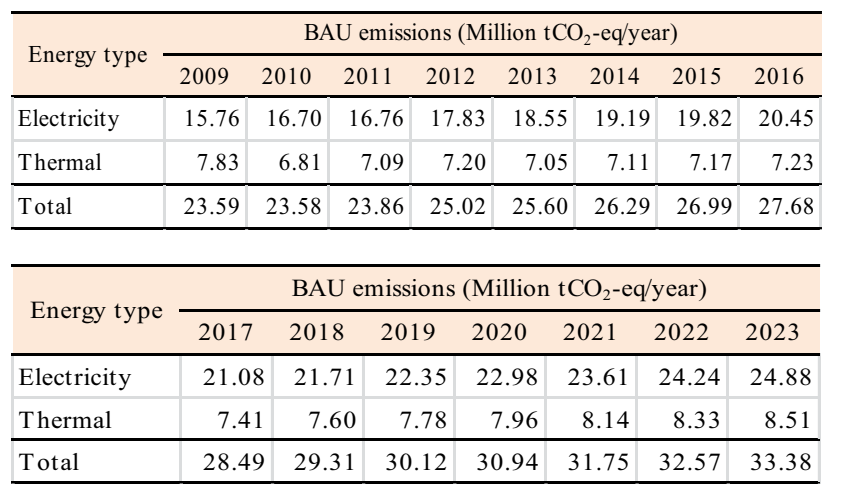

Emissions estimate $=A D_{t} \times E F$

while $\mathrm{AD}=$ Activity data, in energy unit per year

$\mathrm{EF}=$ Emission factor of each fuel type
In this study, we applied the emission factor from Revised 1996 IPCC Guidelines for National Greenhouse Gas Inventories [9] in each thermal energy in BAU.

\section{The GHG mitigation scenario}

In GHG mitigation scenario, we focus to the $\mathrm{GHG}$ reduction potential from the energy efficiency and renewable energy in Bangkok, exclude transport and waste sector, covering the year 2013-2023. All steps present in figure 3.

In this Master Plan, possible mitigation actions are divided into two major categories; (a) actions which BMA can implement by themselves, and (b) actions which are implemented by other stakeholders within Bangkok area. It should be noted that the GHG emission from activities by BMA itself is less than $1 \%$ of the total emission from whole Bangkok area. Therefore, it is important to consider the effect of mitigation actions of category (b). In addition, because it is difficult for BMA to monitor and control the mitigation actions of category (b), we have selected related national plans to calculate GHG mitigation potential in entire Bangkok area.

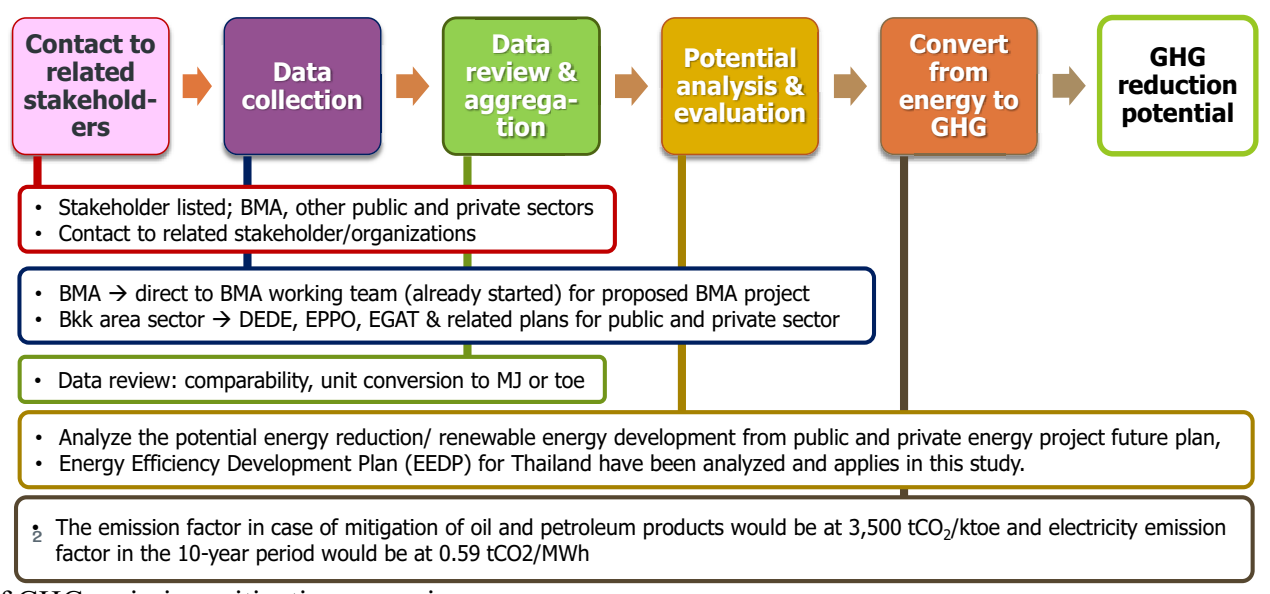

Figure 3. Flow of GHG emission mitigation scenario.

By using the national energy efficiency development plan (EEP) [10] and alternative energy development plan, we assume that the energy reduction potential in Bangkok, in percentage, is as same as the energy reduction of the country. This means that all calculation are based on the national plan but focus in city level.

In case of energy conservation, we can conclude the annual energy reduction which exclude transport and waste sector, in Bangkok as follows;

For electricity conservation, based on EEP

- Residential sector would be at $0.25 \%$ per year,

- Commercial building would be at $1.5 \%$ per year,

- Industry sector would be at $0.81 \%$ per year

For thermal energy conservation, based on EEP

- Commercial building would be at $0.3 \%$ per year,

- Industry sector would be at $0.5 \%$ per year

For emission actor, due to this study focus in the longterm period, hence the future energy consumption proportion would be very flexible. We then applied one universal figure of emission factor, average from various fuel types in Thai energy market. The emission factor in case of mitigation of oil and petroleum products would be at 3,500 $\mathrm{tCO}_{2} /$ ktoe and electricity emission factor in the 10 -year period would be at $0.59 \mathrm{tCO}_{2} / \mathrm{MWh}$ (or 7,000 $\left.\mathrm{tCO}_{2} / \mathrm{ktoe}\right)$. The results in this scenario in Bangkok illustrate in figure 4 and table 3 and the amount of GHG mitigation in Bangkok presents in Table 4.

Table 3. Energy consumption in GHG mitigation scenario.

\begin{tabular}{lrrr}
\hline Type (Million MJ) & \multicolumn{1}{c}{2013} & \multicolumn{1}{c}{2018} & \multicolumn{1}{c}{2023} \\
\hline Electricity & 985.79 & $13,940.89$ & $29,209.39$ \\
Thermal energy & 106.93 & $5,869.96$ & $15,869.22$ \\
\hline Total & $1,092.72$ & $19,810.85$ & $45,078.61$ \\
\hline
\end{tabular}

Table 4. GHG emission in GHG mitigation scenario.

\begin{tabular}{lrrr}
\hline Type (Thousand t-CO2eq) & \multicolumn{1}{c}{2013} & \multicolumn{1}{c}{2018} & \multicolumn{1}{c}{2023} \\
\hline Electricity & 152.17 & $2,236.24$ & $4,692.47$ \\
Thermal energy & 8.86 & 486.34 & $1,314.80$ \\
\hline Total & 161.02 & $2,722.58$ & $6,007.27$ \\
\hline
\end{tabular}


Table 5. Selected countermeasures in GHG mitigation scenario of Bangkok master plan.

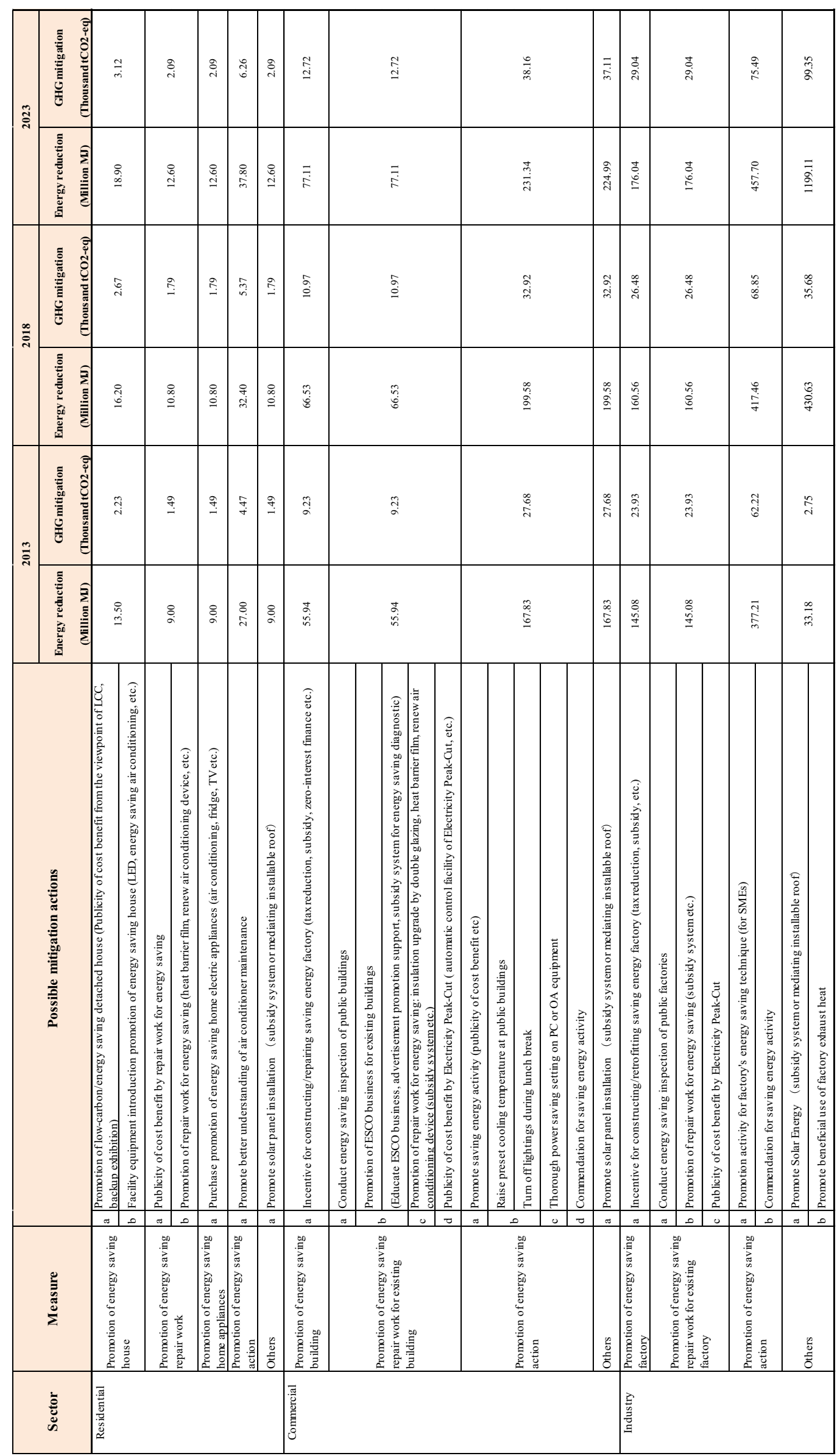




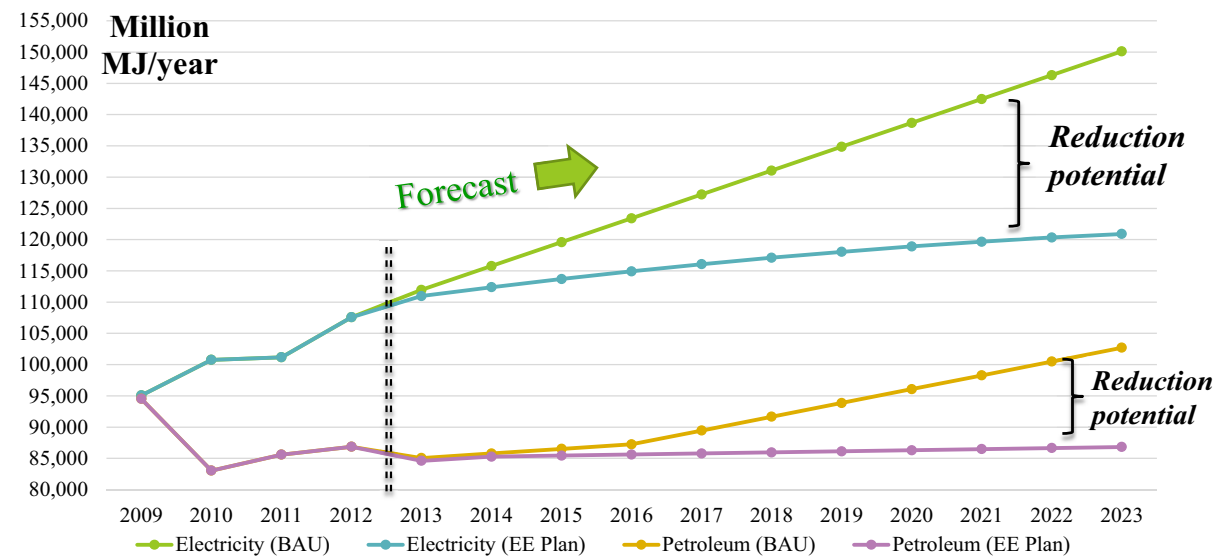

Figure 4. Flow of GHG emission mitigation scenario from 2009 to 2023.

From this scenario, we can conclude that if the EEP can fully implemented, it would reduce the energy by $17.83 \%$ while there is also potential of GHG emission reduction at around $18.00 \%$ from the BAU in the year 2023. However, it must be noticed that it is a potential but not the emission reduction target of the Master Plan.

Selected energy countermeasures including the GHG mitigation is presented in table 5. Most energy measures cover in three economic sectors while there is small potential of renewable energy in Bangkok except the solar roof top. Wind and biomass power plant are not easy to construct. On-ground solar farm is not economicfeasible because of the very expensive land. The energy conservation measures consist of the housekeeping, process improvement, major change equipment, and public awareness concept. The potential of energy conservation and renewable energy measures are adjusted from the national energy conservation potential.

\section{Conclusions}

This study focuses in the developing of city-level GHG mitigation master plan from energy sector in Bangkok. The energy consumption in all economic sectors except transport and waste sector are also investigated and forecasted to be BAU scenario covering year 2013 to 2023 by using trend analysis.

The GHG emission mitigation scenario was then analyzed by applying the energy reduction from the national energy efficiency plan. We can conclude that the energy reduction potential from energy sector would be at $17.83 \%$ while the potential of GHG emission reduction of the city from energy sector would be at around $18.0 \%$ from BAU in 2023 from all energy measures.

\section{Acknowledgement}

The authors would like to thank the Japan International Cooperation Agency (JICA) for all support. We remain culpable for any remaining errors.

\section{References}

1. IPCC AR5, WG1 Report (2014)

2. World bank, Climate change impact and adaptation study for Bangkok Metropolitan region, Final report, World Bank, Washington, DC. (2009)

3. Sanit Wongsa, 2011 Thailand Flood," Journal of Disaster Research, 8, 3, pp. 380-385, (2013)

4. Poaponsakorn, N. and Meethom, P., "Impact of the 2011 Floods, and Flood Management in Thailand," ERIA Discussion Paper Series, ERIA-DP-2013-24, Economic Research Institute for ASEAN and East Asia, (November 2013)

5. BMA, The Bangkok Global Warming Mitigation Action Plan 2007-2012. Bangkok Metropolitan Area Management office, Bangkok, Thailand, (2007)

6. UNFCCC, Communication on Thailand's NAMAs, United Nations Framework Convention on Climate Change. (Nov. 2014). Available: http://unfccc.int/files/meetings/cop_15/copenhagen accord/application/pdf/thailandcphaccord_app2.pdf $\overline{-}$

7. Communication on Thailand's Nationally Appropriate Mitigation Actions (NAMA), Official letter to the UNFCCC. (2014). Available: http://unfccc.int/files/meetings/cop_15/copenhagen accord/application/pdf/thailandcphaccord_app2.pdf

8. Promjiraprawat, $\mathrm{K}$ and Limmeechokchai, $\mathrm{B}$. "Assessment of Thailand's energy policies and $\mathrm{CO}_{2}$ emissions: analyses of energy efficiency measures and renewable power generation", Energies, 5, 8, pp. 3074-3093, (August 2012)

9. DOEB, Energy Business Statistics of Thailand, Department of Energy Business, Thailand. (November 2014). Available: http://www.doeb.go.th/v5/en/service_stat.php

10. IPCC, Revised 1996 IPCC Guidelines for National Greenhouse Gas Inventories, Intergovernmental Panel on Climate Change, 2006. 1st ed. Chichester, U.K.: Wiley, ch. 2, pp. 45-47 (1993)

11. EPPO, Thailand 20-Year Energy Efficiency Plan 2011-2030, Energy Policy and Planning Office, Thailand. (2011). Available: http://www.eppo.go.th/encon/ee20yrs/EEDP_Eng.pdf 